\title{
Implementasi Metode Waterfall Pada Perancangan E-Recycle Bank Pada Dinas Lingkungan Hidup Kabupaten Asahan
}

\author{
William Ramdhan', Riki Andri Yusda², Havid Syafwan ${ }^{3}$, Dian Eka Pratiwi4 \\ 1,4 Program Studi Sistem Informasi, STMIK Royal \\ 2 Program Studi Teknik Komputer, STMIK Royal \\ ${ }^{3}$ Program Studi Manajemen Informatika, STMIK Royal \\ Jl. Prof.H.M Yamin No 173 Telp (0623)41079 \\ william.ramdhan052@gmail.com ${ }^{1}$,rikiandriyusda@gmail.com ${ }^{2}$, havid_syafwan@yahoo.com ${ }^{3}$
}

\begin{abstract}
Asahan Regency is a national strategic area because it has superior sectors such as plantation, marine, agriculture, fisheries and industry. This caused a lot of waste to arise in Asahan Regency. One of the efforts made by the Department of Environment to reduce the volume of waste is to make the Waste Bank an innovative program of community-based waste management. The Waste Bank at the Environmental Service was given the name "Srikandi" which was still less effective and efficient. Because at this time the process is done manually. For that we need to design a system by implementing the waterfall method, which is a sequential software development process, where progress is seen as continuously flowing down (such as waterfalls) through the phases of planning, modeling, implementation (construction), and testing. Hunger by implementing the waterfall method and the C2C e-commerce model in designing and building the E-Recycle Bank system. As a result, the system will make it easier for "Srikandi" Waste Bank officers to manage waste data so as to produce more effective and efficient data, besides that it can also be used as a container for the promotion of waste recycling products for the Asahan Regency
\end{abstract}

Keywords: Waterfall, E-Recycle Bank, C2C E-Commerce

Abstrak-Kabupaten Asahan merupakan kawasan strategis nasional karena memiliki sektor-sektor unggulan seperti perkebunan, kelautan, pertanian, perikanan dan industri. Hal ini menyebabkan akan timbulnya banyaknya limbah di Kabupaten Asahan. Salah satu upaya yang dilakukan Dinas Lingkungan Hidup untuk mengurangi volume limbah adalah membuat Bank Sampah program inovatif pengelolaan sampah berbasis masyarakat. Bank Sampah yang ada di Dinas Lingkungan Hidup itu diberi nama "Srikandi" masih kurang efektif dan efisien. Karena pada saat ini proses dilakukan dengan manual. Untuk itu perlu dirancang sebuah sistem dengan mengimplementasikan metode waterfall, yaitu suatu proses pengembangan perangkat lunak berurutan, dimana kemajuan dipandang sebagai terus mengalir ke bawah (seperti air terjun) melewati fase-fase perencanaan, pemodelan, implementasi (konstruksi), dan pengujian. Haparan dengan mengimplementasikan metode waterfall dan model e-commerce $\mathrm{C} 2 \mathrm{C}$ dalam merancang dan membangun sistem E-Recycle Bank. Hasilnya, dari sistem tersebut akan mempermudah petugas Bank Sampah "Srikandi" dalam mengelola data sampah sehingga menghasilkan data yang lebih efektif dan efisien, selain itu juga dapat digunakan sebagai wadah promosi produk daur ulang limbah bagi masyarakat Kabupeten Asahan

Kata kunci: Waterfall, E-Recycle Bank, E-Commerce C2C

\section{PENDAHULUAN}

Limbah merupakan buangan atau sisa yang dihasilkan dari suatu proses atau kegiatan dari industri maupun domestik (rumah tangga). Berdasarkan kandungan senyawanya, jenis limbah digolongkan menjadi limbah organik dan limbah anorganik. Limbah organik yaitu limbah yang mengandung senyawa-senyawa organik atau yang bersumber dari produk makhluk hidup (tumbuhan dan hewan). Sedangkan limbah anorganik yaitu limbah yang lebih banyak mengandung 
senyawa anorganik. Limbah tersebut akan berdampak buruk bagi kesehatan manusia dan lingkungan apabila tidak dikelola[1]. Pada dasarnya penanganan limbah bukanlah hal yang sulit untuk dilakukan, namun demikian pelaksanaannya perlu kesungguhan dan niat untuk meyelamatkan kesehatan kita. Di era modern ini pengelolaan limbah seolah sangat berbanding terbalik dengan perkembangan dunia IT, hal tersebut tercermin dari semakin banyaknya limbah yang tidak tertangani dan menumpuk di tempat umum bahkan di pinggir jalan. Kabupaten Asahan merupakan kawasan strategis nasional karena di daerah ini terdapat sektor-sektor unggulan seperti perkebunan, kelautan, pertanian, perikanan dan industri. Hal ini yang menyebabkan banyaknya limbah di Asahan. Sesuai dengan visi dan misi Bupati Asahan untuk mewujudkan Asahan yang sehat dengan meningkatkan pelayanan dan kesadaran kesehatan masyarakat, maka salah satu upaya yang dilakukan untuk mewujudkan visi dan misi tersebut adalah dengan mengelola limbah agar tidak mencemari lingkungan. Dinas Lingkungan Hidup Asahan adalah instansi yang mendukung percepatan pembangunan berwawasan lingkungan di Kabupaten Asahan. Salah satu upaya yang dilakukan Dinas Lingkungan Hidup untuk mengurangi volume limbah adalah membuat bank sampah (E-Recyle Bank)program inovatif pengelolaan sampah berbasis masyarakat. Bank Sampah yang ada di Dinas Lingkungan Hidup itu diberi nama "Srikandi". Bank Sampah "Srikandi" merupakan salah satu badan usaha yang bergerak di bidang pengelolaan sampah maka tentunya selalu terjadi proses transaksi sampah setiap harinya. Menurut Peraturan Menteri Lingkungan Hidup RI Nomor 13 Tahun 2012, bank sampah adalah tempat pemilahan dan pengumpulan sampah yang dapat didaur ulang dan atau diguna ulang yang memiliki nilai ekonomi. Bank Sampah merupakan konsep pengumpulan sampah kering dan dipilah serta memiliki manajemen layaknya perbankan, tapi yang ditabung bukan uang melainkan sampah. Seperti halnya sebuah bank komersil, dimana seseorang bias membuka rekening di sebuah bank sampah[2].

Berdasarkan perihal tersebut maka perlunya sebuah sistem E-Recycle Bank untuk mendukung program Dinas Lingkungan Hidup Asahan dalam menangani limbah di Kabupaten Asahan. Sistem E-Recycle Bank pada Dinas Lingkungan Hidup nantinya akan mengelola data pada Bank Sampah "Srikandi" yang memiliki fitur iklan baris di Asahan yang difokuskan untuk membeli dan menjual produk daur ulang limbah secara online. Mekanismenya nanti nasabah akan diberikan buku tabungan untuk mencatat transaksi tabungan setiap penyetoran sampah[3]. Selain itu nasabah juga dapat membeli sampah yang ada untuk didaur ulang dirubah kedalam bentuk yang lebih bernilai dan bemanfaat. Hasilnya dapat dijual kembali melalui sistem E-Recycle Bank Srikandi. Sehingga sistem ini diharapkan dapat meningkatkan kepedulian masyarakat terhadap lingkungan dan meningkatkan perekonomian masyarakat sekaligus mempererat hubungan antar warga di Kabupaten Asahan.

\section{METODOLOGI PENELITIAN 2.1 Kerangka Penelitian}

Perancangan E-Recycle Bank Pada Dinas Lingkungan Hidup (William Ramdhan) | 1011 
Kerangka penelitian adalah konsep suatu penelitian yang menghubungkan antara visualisasi satu variabel denga variabel lainnya, sehingga penelitian menjadi tersusun secara sistematis dan dapat diterima oleh semua pihak. Berdasarkan dari uraian latar belakang, perumusan masalah, dan teori-teori yang telah dijelaskan sebelumnya, maka kerangka penelitian sebagai berikut:

a. Identifikasi Masalah

Masalah yang diidentifikasi dalam penelitian ini adalah masih manualnya sistem pengelolaan data limbah yang digunakan oleh Dinas Lingkungan Hidup Asahan serta kurangnya kepedulian masyarakat terhadap limbah.

b. Analisa Masalah

Setelah mengidentifikasi masalah yang akan diteliti, maka masalah-masalah tersebut perlu dianalisis seperti analisis kelemahan sistem, analisis kebutuhan sistem, dan analisis kelayakan sistem. Hal ini perlu dilakukan agar tidak ada kendala dalam pemecahan masalah tersebut.

c. Studi Literatur

Selain data yang diperoleh dari tempat penelitian, penulis juga mengumpulkan literatur-literatur yang berhubungan dengan penelitian, yaitu mengumpulkan buku-buku dan jurnal yang berkaitan dengan topik yang akan dibahas.

d. Pengumpulan Data

Data dikumpulkan dari berbagai sumber yang ada. Pengumpulan data pada penelitian ini dilakukan dengan tiga metode, yaitu studi literatur, wawancara, dan observasi.

e. Analisa Sistem

Setelah melakukan pengumpulan data melalui wawancara dan observasi, penulis menganilisis sistem yang sedang berjalan pada Bank Sampah "Srikandi" di Dinas Linngkungan Hidup.

f. Perancangan Sistem

Pada tahap perancangan sistem, penulis menganalisis kebutuhan sistem kemudian merancangan sistem yang akan dibuat menggunakan UML (Unified Modeling Language). Tahap akhir yang dilakukan pada perancangan ini adalah perancangan Black Box sebagai media untuk mengkomunikasikan proses dan prosedur terhadap pemrograman.

g. Pembuatan Program

Pembuatan program dilakukan dengan menginstalasi software yang mendukung implementasi atau pengujian pada penelitian ini. Selanjutnya program akan dibuat menggunakan bahasa pemrograman PHP.

h. Pengujian Sistem

Pengujian sistem merupakan tahap dimana akan diketahui apakah aplikasi yang dirancang sudah layak atau tidak digunakan untuk pengelolaan data pada Bank Sampah "Srikandi" Dinas Lingkungan Hidup Asahan.

i. Implementasi Sistem Implementasi merupakan tahapan akhir dalam sebuah sistem setelah dinyatakan layak untuk digunakan.

\subsection{Metode Penelitian}


Metode waterfall terdiri dari lima tahapan yaitu System Engineering, Requirement Analysis, Design, Coding, dan Testing. Tahapan tahapan dari metode waterfall pada penelitian ini adalah sebagai berikut[4]:

a. System Engineering

Melakukan pengumpulan data dan penetapan kebutuhan semua elemen system. Langkah awal yang dilakukan adalah melakukan studi literatur, observasi, dan wawancara.

b. Requirement Analysis

Tahap melakukan analisis terhadap permasalahan yang dihadapi dan menetapkan kebutuhan perangkat lunak yang akan dibangun sesuai dengan tahap yang telah dilakukan sebelumnya. Menganalisa kebutuhan dengan menggunakan use case diagram dan didefinisikan kembali dengan menggunakan activity diagram.

c. Design

Tahap ini menentukan bagaimana sistem akan dibangun, mulai dari perangkat keras dan perangkat lunak yang digunakan, program, database, laporan serta gambaran hasil laporan yang dihasilkan. Konsep yang telah disusun pada tahap analisa ditinjau kembali dan disempurnakan. Tahap design ini meliputi pembuatan sequence diagram, class diagram dan desain antarmuka atau design interface.

d. Implementasi (coding)

Tahap ini merupakan tahap lanjutan dari tahap sebelumnya yaitu design. Pada tahap ini merupakan pembuatan program yang akan dibangun menggunakan bahasa pemograman PHP dengan menggunakan Adobe Dreamweaver serta MySQL sebagai database.

e. Testing

Pada tahap testing akan dilakukan pengujian terhadap sistem yang telah dibangun. Pengujian yang dilakukan dengan menggunakan metode Black Box. Tahapan ini dilakukan untuk memastikan bahwa sistem yang dibangun telah berjalan sesuai dengan yang diharapkan.

\section{HASIL DAN PEMBAHASAN}

\subsection{Aliran Sistem Informasi}

Pada perancangan sistem yang akan dibagun nantinya aplikasi E-Recycle Bank yang mana aplikasi E-Recycle Bank akan dirancang untuk memudahkan karyawan dalam hal melakukan pengolahan data transaksi nasabah, untuk lebih lengkapnya dapat dilihat alur analisis sistem informasi baru yang akan dirancang dibawah ini.

a. Calon nasabah bawa persyaratan seperti KTP ke bank sampah untuk menjadi nasabah

b. Karyawan menerima pesyaratan yang di bawa Calon nasabah selanjutnya untuk diinputkan dalam Database

c. Setelah menginputkan data calon nasabah ke dalam Database selanjutnya Karyawan mencetak laporan data nasabah untuk diberikan ke Pimpinan 
d. Pimpinan menerima laporan data nasabah dan langsung memeriksa laporan data nasabah setelah diperiksa Pimpinan menandatangani laporan data nasabah untuk diberikan ke Karyawan

e. Karyawan menerima laporan data nasabah yang ditandatangani pimpinan untuk di jadikan arsip.

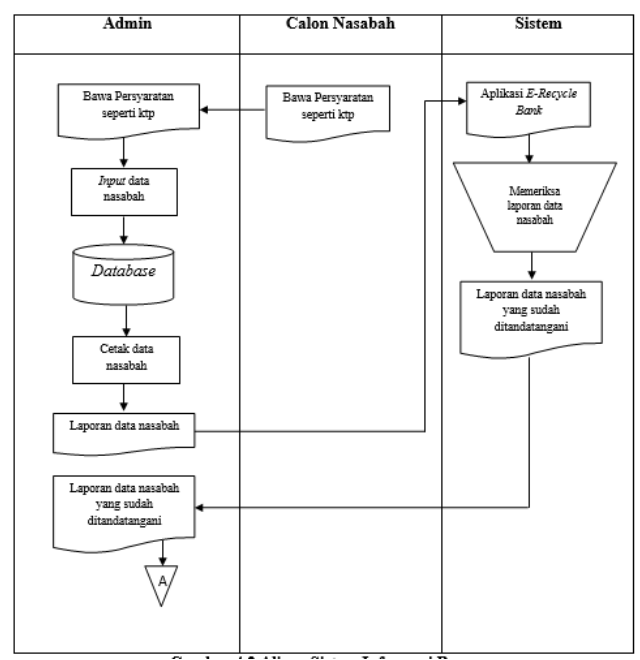

Gambar 1. Aliran Sistem Informasi Baru

\subsection{Analisis Sistem Usulan}

Secara garis besar, proses sistem yang akan dirancang digambarkan dengan Use Case Diagram yang terdapat pada Gambar 2.

a. Admin menginputkan data calon nasabah kemudian memberikan akun ke Nasabah untuk bisa login ke sistem Nasabah

b. Admin mengelola seluruh data yang ada di sistem di mulai dari data nasabah, data sampah dari nasabah, data transaksi dan data inventory

c. Admin cetak laporan data transaksi dan inventory

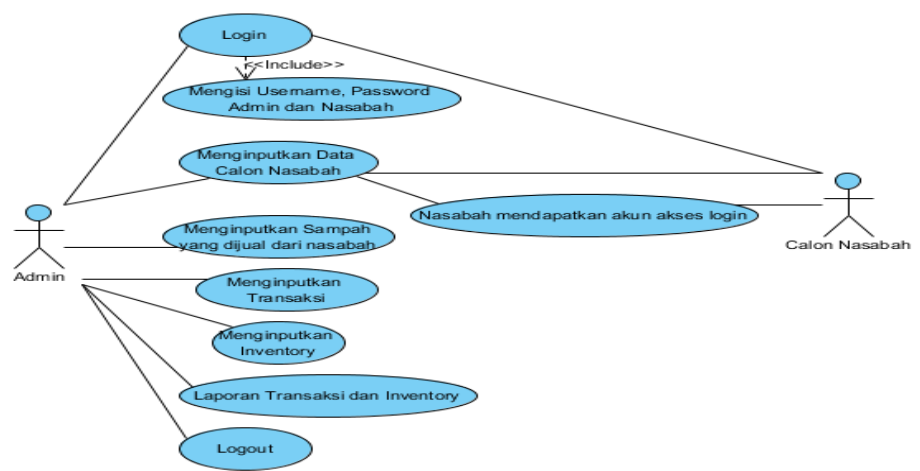

Gambar 2. Use Case Diagram Sistem Yang Diusulkan

\subsection{Tampilan Hasil Pengujian}

Desain tampilan sistem dilakukan agar pengguna yang beroperasi menjalankan sistem lebih menarik dan mudah dimengerti untuk mempelajarinya 
dan menggunakannya. Berikut ini tampilan sistem yang dirancang pada sistem aplikasi E-Recycle Bank.

a. Tampilan Menu Login Admin dan Login Nasabah

Pada gambar dibawah ini menjelaskan tampilan menu login admin dan nasabah aplikasi E-Recycle Bank yang terdiri dari username dan password tersebut.

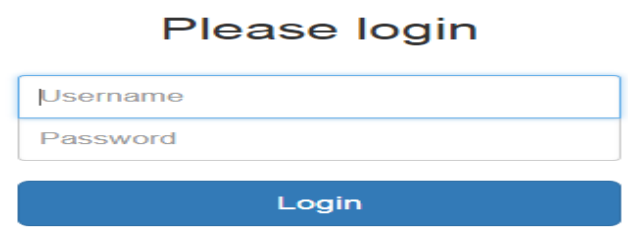

Gambar 3. Tampilan Menu Login Admin dan Nasabah

b. Tampilan Halaman Depan Aplikasi E-Recycle Bank

Pada gambar dibawah ini menjelaskan tentang tampilan halaman depan aplikasi E-Recycle Bank.

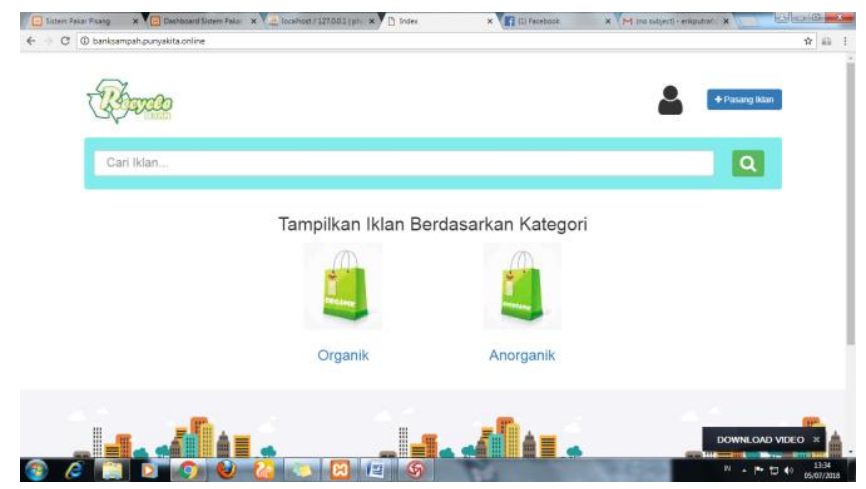

Gambar 4. Tampilan Halaman Depan Aplikasi E-Recycle Bank

c. Tampilan Halaman Admin

Pada gambar dibawah ini menjelaskan tentang halaman admin pada aplikasi $E$ Recycle Bank yang terdiri dari menu nasabah, sampah, transaksi, inventory dan logout seperti pada gambar dibawah ini.

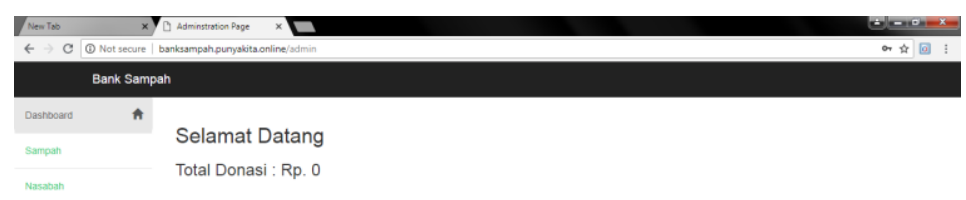

Gambar 5. Tampilan Halaman Admin 
d. Tampilan Input Data Nasabah

Pada gambar dibawah ini menjelaskan tampilan input data calon nasabah

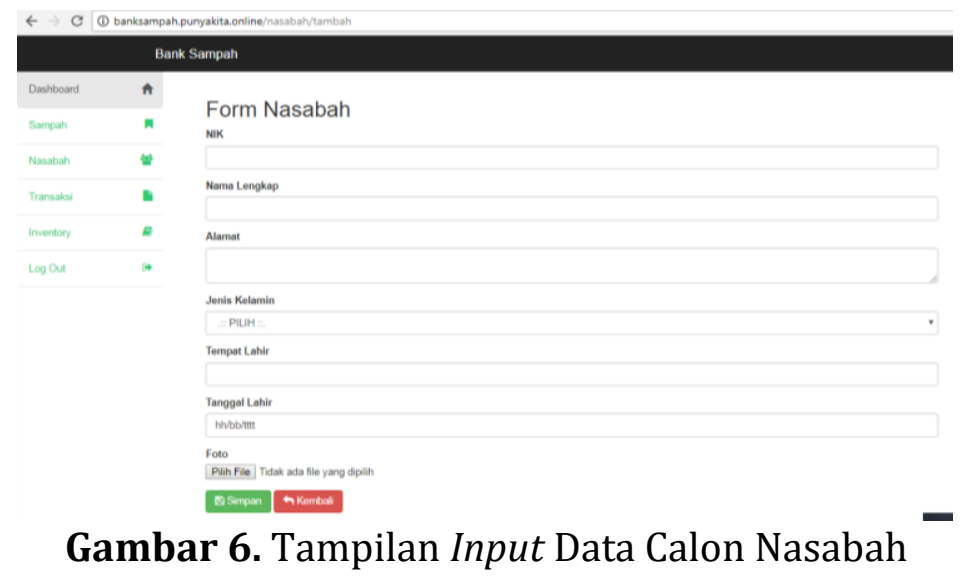

e. Tampilan Input Data Sampah

Pada gambar dibawah ini menunjukan proses input data produk sampah nasabah yang dijual.

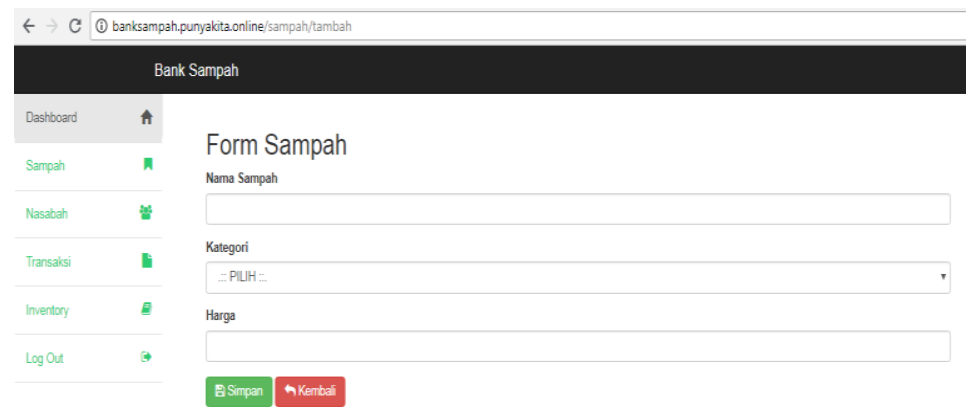

Gambar 7. Tampilan Input Data Sampah

f. Tampilan Input Data Transaksi

Pada gambar dibawah ini menunjukan proses input data transaksi produk sampah nasabah yang terjual.

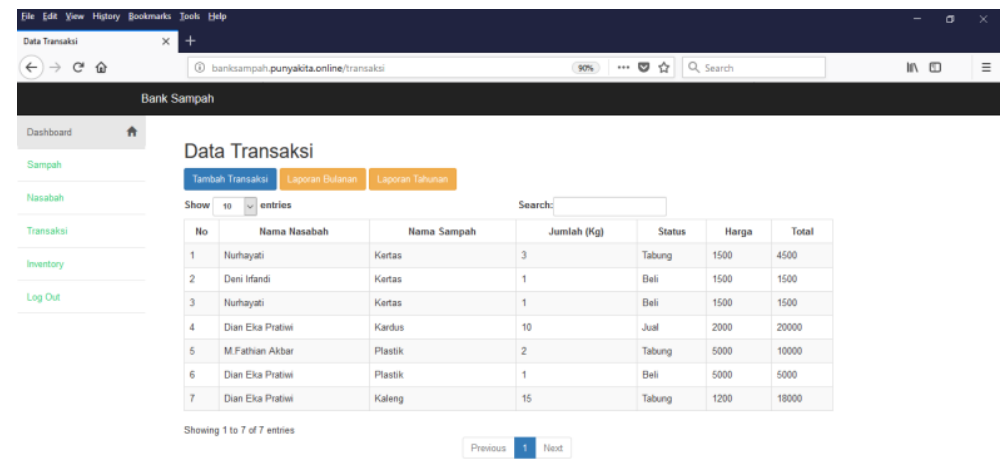

Gambar 8. Tampilan Input Data Transaksi

Perancangan E-Recycle Bank Pada Dinas Lingkungan Hidup (William Ramdhan) | 1016 
g. Tampilan Laporan Data Inventory

Pada gambar dibawah ini menunjukan cetak laporan data inventory berdasarkan bulan dan tahun.

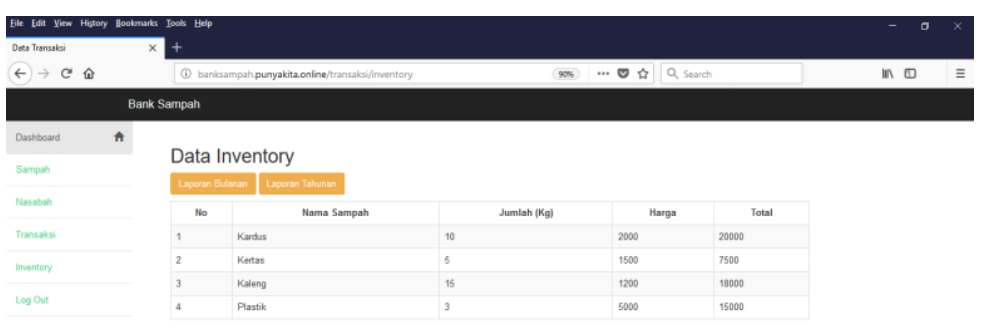

Gambar 9. Tampilan Cetak Laporan Data Inventory

\section{KESIMPULAN}

Adapun kesimpulan yang telah didapat setelah dilakukan pengujian terhadap sistem adalah:

a. Sistem yang rancang ini hanya ditujukan untuk mengolah tabungan data sampah organik maupun non organik.

b. Sistem ini merupakan sebagai media untuk meningkatkan dan memanfaatkan limbah sampah menjadi nilai jual yang baik

\section{DAFTAR PUSTAKA}

[1] D. P. Kusuma, Y. Astuti, and C. Catur, "SISTEM PENGOLAHAN DATA BANK SAMPAH ( STUDY KASUS : BANK SAMPAH BANGKIT PONDOK I NGEMPLAK SLEMAN )," vol. 21, no. 1, pp. 32-41, 2017.

[2] T. Bank and S. Ceria, "Pembangunan Sistem Informasi Pengolahan Data Pada Tabungan Bank Sampah 'Ceria' Purwokerto," vol. 8, no. 2, pp. 1-17, 2015

[3] B. S. Samawa, B. Web, D. I. Bank, and S. Samawa, "Membangun Sistem Informasi Pengelolahan Data Nasabah Berbasis Web Di," no. November, 2017.

[4] I. Fahrurrozi, P. Studi, I. Komputer, and U. G. Mada, " : STUDI PROSES PEMODELAN SOFTWARE DENGAN METODE WATERFALL DAN EXTREME PROGRAMMING."

[5] Windarto, Y. (2016). Pengaruh usability factor website e-commerce model B2C terhadap kepercayaan user. Jurnal Sistem Informasi, 8(2):1107-1108. 